\title{
A expansão da educação superior no Amapá: um estudo sobre o Procampo na UNIFAP
}

\author{
Heliadora Georgete Pereira da Costa ${ }^{1}$ e Roni Mayer Lomba ${ }^{2}$
}

1 Mestre em Desenvolvimento Regional da UNIFAP, Especialista em Gestão Escolar e Licenciada em Pedagogia. Extensionista Social na Agência de Pesca do Estado do Amapá, Brasil. E-mail: heliadoracosta@gmail.com

2 Doutor em Geografia. Professor da UNIFAP, vinculado no Colegiado de Geografia e do Programa de Mestrado em Desenvolvimento Regional, Brasil. E- mail: ronimayer@hotmail.com

RESUMO: Este artigo tem como objetivo apresentar reflexões sobre a formação inicial dos educadores do campo no Estado do Amapá a partir da implantação do curso de Licenciatura em Educação do Campo na Universidade Federal do Amapá (UNIFAP). Para este estudo, a metodologia utilizada foi a pesquisa bibliográfica para subsidiar a revisão de literatura e a documental com a análise do projeto pedagógico e do memorial dos cursos, a fim de discutir a materialização e os impactos desta política na formação dos professores. Os resultados revelam a importância dos cursos ofertados aos docentes que atuam nas escolas do campo amapaense. A formação destes professores acontece com currículo, avaliação, espaço e tempo específicos, alicerçando-se na metodologia da Alternância Pedagógica, respeitando-se as particularidades da educação do campo. Os cursos de Licenciatura em Educação do Campo são um avanço para o Estado do Amapá, uma vez que os sujeitos do campo foram historicamente excluídos das políticas públicas de educação no Brasil.

Palavras-chave: Educação do Campo. Procampo. Movimentos Sociais. Formação de Educadores.

\section{The expansion of higher education in Amapá: a study on Procampo at the Federal University of Amapá}

ABSTRACT: This article aims to present reflections on the initial training of rural educators in the State of Amapá through the implementation of Licenciate degree in Rural Education at the Federal University of Amapá (UNIFAP). For this study, the methodology used was the bibliographic research to subsidize the review of literature and documents with the analysis the pedagogical Project and the memorial of the courses of study in order to discuss the materialization and the impact of this policy on teacher education. The results show the importance of the degrees offered to teachers Who work in the rural schools of the State of Amapá. The education of these teachers happens with curriculum, assessment, specific space and time, basing on the methodology of the pedagogy of Alternation, respecting the particularities of rural education. The licentiate degrees of Rural Education are a breakthrough for the State of Amapá, since the subjects of the rural education were historically excluded from public education policies in Brazil.

Keywords: Rural Education, Procampo. Social Movements. Teacher Education. 


\section{INTRODUÇÃO}

Este artigo tem como objeto de estudo o Programa de Apoio à Formação Superior em Licenciatura em Educação do Campo (PROCAMPO), política pública de educação que incentiva a implementação de cursos de Licenciatura em Educação do Campo e será discutido enquanto política de educação que nasceu das pressões sociais que floresceram na década de 1970 e intensificaram-se em 1990.

A proposta do Procampo foi elaborada pelo Grupo Permanente de Trabalho de Educação do Campo (GPT) ou Comissão Nacional de Educação do Campo (CONEC). O referido programa foi aprovado pelo Ministério da Educação (MEC) em 2006, com o objetivo de financiar a oferta de cursos de Licenciatura em Educação do Campo nas Instituições de Ensino Superior (IES), visando à formação inicial de docentes para atuarem nas escolas do campo, prioritariamente, nos anos finais do ensino fundamental e no ensino médio da educação básica.

A implementação do programa ocorreu em 2007 por meio de projeto piloto implantado na Universidade de Brasília (UNB), Universidade Federal da Bahia (UFBA), Universidade Federal de Sergipe (UFS) e Universidade de Minas Gerais (UFMG). Após esta experiência inicial, o MEC por meio da Secretaria de Educação Continuada, Alfabetização, Diversidade e Inclusão (SECADI) lançou, em 2008, o primeiro edital convocando as IES públicas do País para submeter projetos para a oferta de graduação em Licenciatura em Educação do Campo (TAFFAREL; JÚNIOR, 2011).

As bases legais dos cursos de LEDOC encontram respaldo no Parecer CNE/CP №. 09/2001 e Resolução CNE/CP №. 1 de 18 de fevereiro de 2002 que instituem as Diretrizes Curriculares Nacionais para a Formação de Professores da Educação Básica, em nível superior, curso de licenciatura, de graduação plena. O despreparo dos professores é apontado no parecer mencionado como um dos fatores que dificultam o avanço da Educação Básica no País; portanto, ele "[...] apresenta a base comum de formação docente expressa em diretrizes, que possibilitem a revisão criativa dos modelos hoje em vigor" (BRASIL, 2001, p. 4).

Outras legislações que amparam as Licenciaturas em Educação do Campo são o Parecer CNE/CEB №. 36/2001 e a Resolução CNE/CEB №. 1/2002, que Instituem as DOEBEC, Resolução CNE/CEB №. 2, de 28 de abril de 2008, que propõe as Diretrizes Complementares, Normas e Princípios para - Desenvolvimento de Políticas Públicas de Atendimento da Educação Básica do Campo; Parecer CNE/CEB №. 1/2006, que estabelecem os dias letivos para a aplicação da Pedagogia de Alternância nos Centros Familiares de Formação por Alternância (CEFFA); Decreto №. 7.352, de 04 de novembro de 2010, que dispõe sobre a Política de Educação do Campo e o Programa Nacional de Educação na Reforma Agrária-PRONERA e o Parecer CNE/CP №. 28 de 2 de outubro de 2001 e Resolução CNE/CEB №. 2, de 19 de Fevereiro de 2002, que define o período de duração e a carga horária dos cursos de formação de professores da Educação Básica, em nível superior, licenciatura plena. (TAFFAREL; JÚNIOR, 2011).

O Procampo financiou, no Estado do Amapá, desde o ano de 2009, o projeto de Licenciatura em Educação do Campo (LEDOC), na Universidade Federal do Amapá, com foco em docência multidisciplinar em Física e Biologia, que atendeu o Município 
de Laranjal do Jarí. Em 2010, esse mesmo curso passou a ser executado, em Mazagão, no campus da UNIFAP.

$O$ interesse na investigação dos cursos de Licenciatura em Educação do Campo justifica-se pela carência de pesquisas sobre a formação dos educadores que atuam nas escolas do campo no Estado do Amapá, partindo da própria dinâmica do campo, de seus limites e de suas possibilidades. Além disso, o Procampo será evidenciado neste estudo como uma política pública que contribui para o reconhecimento do educadorsujeito do campo historicamente marginalizado pelas políticas elaboradas pelo Estado brasileiro. O Procampo surgiu como demanda dos movimentos sociais para garantir o direito dos educadores do campo de acessar a Educação Superior.

Outro aspecto relevante para a formulação desta investigação está relacionado à escassez de pesquisas voltadas para a educação que tenha o olhar sobre a participação dos movimentos sociais no campo amapaense, com base nessa perspectiva este trabalho será relevante para a sociedade acadêmica, dando ênfase ao Estado do Amapá, sem negar a influência do contexto nacional.

Este artigo está sistematizado, considerando uma breve reflexão sobre a educação do campo no contexto da década de 1990, procurando compreender a importância dos movimentos sociais na luta pela melhoria da educação do campo e a discussão dos cursos de licenciatura apoiados pelo Procampo na UNIFAP.

O objetivo deste artigo é apresentar reflexões sobre a formação inicial dos educadores do campo no Estado do Amapá a partir da implantação dos cursos de Licenciatura em Educação do Campo, vinculados à
UNIFAP.

\section{EDUCAÇÃO DO CAMPO E FORMAÇÃO DOCENTE: O PROCAMPO NA AMAZÔNIA AMAPAENSE}

As políticas públicas para a educação do campo devem ser entendidas dentro do contexto das mudanças que ocorreram nos anos 90 , oriundas da política neoliberal que afetou e transformou o cenário político, econômico e social mundial e do Brasil.

Como reflexo dessas transformações, a educação foi envolvida por estratégias e reformas orientadas por interesses do capital. Herkenhoff $(2005$, p. 8) expõe que a "educação não é um tema isolado, mas decorre de decisões políticas fundamentais. Isto é, a educação é uma questão visceralmente política". A educação, então, constituiu parte das estratégias políticas em função dos interesses do desenvolvimento econômico do País.

Foi nesse contexto que a Educação do Campo nasceu, com base nas reivindicações dos movimentos sociais do campo, nos anos de 1990. Ela surgiu como resistência ao avanço do capital no campo, como protesto às desigualdades históricas tanto sociais quanto econômicas dos camponeses. Nesse sentido, a Educação do Campo traz como elementos caracterizadores o combate à marginalização econômica e social e a busca da autonomia camponesa.

Ainda na década de 1990, nasceu o movimento Por uma Educação do Campo com a finalidade de garantir os direitos educativos dos sujeitos do campo. Como afirma Vendramini (2007, p. 123):

É preciso compreender que a educação do campo não emerge no vazio e nem é 
iniciativa das políticas públicas, mas emerge de um movimento social, da mobilização dos trabalhadores do campo, da luta social. É fruto da organização coletiva dos trabalhadores diante do desemprego, da precarização do trabalho e da ausência de condições materiais de sobrevivência para todos.

Das lutas sociais surgiu, então, a concepção de Educação do Campo que se contrapõe à visão fragmentada do urbano em detrimento do rural que, ainda, prevalece na sociedade brasileira. Nessa concepção, o campo passou a ser visto como um território construído pelos seus sujeitos, com características e identidade própria, concebido com base na organização da população como uma forma de resistência às imposições da lógica capitalista, pois, de acordo com Molina (2010, p. 7), esse momento faz "parte das estratégias de resistência à expropriação provocada pelo capital" que vê o campo apenas como lugar de geração de lucros.

Os movimentos sociais do campo buscam uma educação voltada para atender suas necessidades, ou seja, visam superar as condições adversas caracterizadas pelas relações de poder, que denotam a exclusão da população e que foram historicamente construídas. Segundo Caldart (2010, p. 105):

a gênese da educação do campo é fruto da denúncia de processos de exclusão da terra, da educação, da moradia, da cultura e da vida. É fruto da prática coletiva que, ao denunciar, exercita a participação coletiva e efetiva categorias que são fundantes da política pública orientada para a transformação social.
A partir da articulação dos trabalhadores do campo com as organizações não governamentais, como igrejas, intelectuais, movimentos e organizações sociais, importantes conquistas foram alcançadas para atender a educação do campo. Uma dessas conquistas foi a aprovação das Diretrizes Operacionais para a Educação Básica nas Escolas do Campo (DOEBEC) - Resolução no. 01/2002/CNE/MEC, resultado das reivindicações do movimento Por uma Educação do Campo. De acordo com o Parecer no. 36/2001 do CEB/CNE/MEC, que criou as Diretrizes para a Educação do Campo, os:

movimentos sociais do campo propugnam por algo que ainda não teve lugar, em seu estado pleno, porque perfeito no nível das suas aspirações. Propõem mudanças na ordem vigente, tornando visível, por meio das reivindicações do cotidiano, a crítica ao instituído e o horizonte da educação escolar inclusiva (BRASIL, 2001, p. 09).

No ano de 1997, o movimento Por uma Educação do Campo organizou o I Encontro Nacional de Educadores e Educadoras da Reforma Agrária (I ENERA) e em 1998, a I Conferência denominada Por uma Educação Básica do Campo, retomando as discussões sobre a Educação do Campo, no intuito de que o Estado atendesse as solicitações que surgiram a partir dessa conferência. Na avaliação de Caldart (2004, p. 13), a referida Conferência foi o "momento de batismo coletivo de um novo jeito de lutar e de pensar a educação para o povo brasileiro que trabalha e vive no e do campo".

A carência de políticas públicas foi um dos fatores que impulsionaram os movimentos camponeses a lutar por melhorias 
para a população do campo, muitas vezes explorada, marginalizada, sem teto, sem terra, sem acesso aos serviços essenciais, aos bens culturais e educacionais. Como afirma Martins (2000, p.100):

a exclusão se tornou parte integrante da reprodução do capital [...] há quem fale numa espécie de auxílio estatal à pobreza que dispensaria a reforma agrária, custosa, e asseguraria a sobrevivência dos pobres em condições mínimas sem necessidade de pagar o custo de grandes transformações econômicas e sociais como a reforma agrária.

A Educação do Campo revela as mazelas sociais que a população camponesa carrega, particularmente, quanto ao ensino ofertado nas escolas do campo. A falta de investimento na formação dos docentes apresenta-se como um dos fatores que contribuem para a baixa qualidade do ensino nas escolas do campo brasileiras.

A formação inicial dos professores em nível de educação superior é uma política recente, vista pelos movimentos sociais como uma ação de fortalecimento da educação e da escola do campo. Enquanto política pública, os cursos do Procampo têm como base legal o Decreto no 7.352/2010 que estabelece:

Art. $5^{\circ} \mathrm{A}$ formação de professores para a educação do campo observará os princípios e objetivos da Política Nacional de Formação de Profissionais do Magistério da Educação Básica, conforme disposto no Decreto $n^{\circ} 6.755$, de 29 de janeiro de 2009, e será orientada, no que couber, pelas diretrizes estabelecidas pelo ConseIho Nacional de Educação.

$\S 1^{\text {o }}$ Poderão ser adotadas metodologias de educação à distância para garantir a adequada formação de profissionais para a educação do campo.

$\S 2^{\circ}$ A formação de professores poderá ser feita concomitantemente à atuação profissional, de acordo com metodologias adequadas, inclusive a pedagogia da alternância, e sem prejuízo de outras que atendam às especificidades da educação do campo, e por meio de atividades de ensino, pesquisa e extensão.

$\S 3^{\circ}$ As instituições públicas de ensino superior deverão incorporar nos projetos político-pedagógicos de seus cursos de licenciatura os processos de interação entre o campo e a cidade e a organização dos espaços e tempos da formação, em consonância com as diretrizes estabelecidas pelo Conselho Nacional de Educação. (BRASIL, 2010).

O Decreto no. 7.352/2010 dispõe sobre a política de Educação do Campo e sobre a necessidade de formação específica para os professores, o que refletirá na melhoria dos indicadores de aprendizagem nas escolas do campo, o que passou a ser materializado com os cursos de LEDOC pelo Procampo.

O Procampo é uma política de Estado legitimada pelo MEC no ano de 2006, por meio da Secretaria de Educação Continuada, Alfabetização, Diversidade e Inclusão (SECADI) com a colaboração da Secretaria de Educação Superior (SESU) e o Fundo Nacional de Desenvolvimento da Educação (FNDE). O objetivo do programa é apoiar a implantação de cursos de licenciaturas em Educação do Campo nas instituições públicas de ensino superior do País.

É um programa de formação voltado para os educadores que atuam nas escolas do campo. Está vinculado às instituições públicas de ensino superior, selecionadas por 
meio de projetos apresentados conforme editais de seleção da SECADI/MEC. As Licenciaturas em Educação do Campo abrangem diferentes áreas do conhecimento, além de considerar as especificidades regionais e locais, fugindo à lógica de formação que embasa as licenciaturas clássicas.

Na Lei de Diretrizes e Bases da Educação Nacional (LDBEN) no. 9.394/96, em seu artigo 62, está estabelecido que:

A formação do docente para atuar na educação básica far-se-á em nível superior, em curso de licenciatura, de graduação plena, em universidades e institutos superiores de educação, admitida, como formação mínima para o exercício do magistério na educação infantil e nos cinco primeiros anos do ensino fundamental, a oferecida em nível médio, na modalidade normal (BRASIL, 1996, 35).

Baseando-se nas diretrizes legais da LD$B E N$ e da DOEBEC é que o Procampo se justificou, passando a ser divulgado e expandido para todos os estados brasileiros, como ocorreu com o Estado do Amapá no ano de 2008, por meio do projeto apresentado pela UNIFAP e selecionado pela SECADI/MEC para o financiamento e oferta do Curso de Licenciatura em Educação do Campo Docência Multidisciplinar em Física e Biologia, implantado no Município de Laranjal do Jarí $i^{1}$, ao sul do Estado, e, posteriormente,

\footnotetext{
${ }^{1}$ O Município de Laranjal do Jarí possui uma área de $31.170 \mathrm{~km} 2$, localizado cerca de $276 \mathrm{~km}$ da capital, Macapá. Localiza-se na região sudoeste do Estado do Amapá à margem esquerda do Rio Jari, em uma região denominada Vale do Jari, nas divisas com os municípios amapaenses de Vitória do Jarí, Mazagão, Pedra Branca do Amapari e Almerim no Pará. Está na faixa de fronteira entre o Suriname e a Guiana Francesa. Com uma população estimada em 2014 de 44.777 habitantes é o terceiro município amapaense mais populoso (IBGE, 2014).
}

estendido para o campus da universidade no Município de Mazagão . O projeto do referido curso foi conduzido pelo "edital de Convocação no 2, de 23 de abril de 2008SECADI/MEC, publicado no Diário Oficial da União de 24 de abril de 2008, seção 3, página 30 e Aprovado no edital no 06 SECADI/MEC, de 03 de outubro de 2008" (UNIFAP, 2011, p. 21).

De acordo com o Projeto Político Pedagógico do Procampo:

\section{O Projeto "Licenciatura em Educação no} Campo" da UNIFAP objetiva realizar um curso em que a formação é mediada pela produção do conhecimento ancorado/mobilizado na experiência de vida do professor e de sua identidade, construindo-se a partir da compreensão de uma prática interativa e dialógica entre $o$ indivíduo e o coletivo relacionada à "rede de ciência e tecnologia disponível na sociedade e nos movimentos sociais em defesa de projetos que associem as soluções exigidas por essas questões da qualidade social de vida coletiva no país" (UNIFAP, 2011, p. 9).

Ainda, segundo o PPC, o ingresso ao Curso de Licenciatura em Educação do Campo é realizado através de processo seletivo definido por meio de edital específico, sendo que os exames são realizados pela UNIFAP e compreendem os conhecimentos relativos ao ensino médio, tem um quantitativo fixo de vagas que "também podem ser preenchidas através de seleção, realizada

\footnotetext{
${ }^{2}$ O Município de Mazagão localiza-se ao sul do Estado do Amapá, compreendendo uma área é de $13,131 \mathrm{~km}^{2}$. Estima-se que tenha uma população estimada de 19.157 habitantes em 2014. Limita-se com os municípios de Pedra Branca do Amapari, Porto Grande, Santana, Vitória do Jari, Laranjal do Jari e com a foz do rio Amazonas (IBGE, 2014).
} 
pelas Secretarias Municipais de Educação, com a indicação de educadores do campo, da rede de ensino, que não possuam curso de graduação" (UNIFAP, 2011, p. 15).

A licenciatura em educação do campo efetivada nos municípios amapaenses vem ao encontro da realidade das escolas e das comunidades do campo, quase sempre, atingidas pela marginalização e exclusão. A formação inicial dos educadores é um importante indicador de qualidade que pode contribuir para a melhoria dos níveis de aprendizagem dos estudantes da Educação Básica das comunidades rurais atendidas.

\section{METODOLOGIA}

Este estudo fundamenta-se na abordagem qualitativa e adota como metodologia as pesquisas de campo, bibliográfica e documental. Na pesquisa de campo utilizou entrevistas semi estruturadas direcionadas aos egressos das turmas executadas nos Municípios de Mazagão e Laranjal do Jari.

A pesquisa bibliográfica objetiva subsidiar a revisão de literatura, trazendo o embasamento teórico necessário ao trabalho e tecendo paralelo entre os autores que tratam o tema da educação do campo tais como (CALDART, 2004; MOLINA, 2010; VENDRAMINI, 2007). Segundo Oliveira (2007, p. 69), a pesquisa bibliográfica é um tipo de "estudo direto em fontes científicas, sem precisar recorrer diretamente aos fatos/fenômenos da realidade empírica". A pesquisa bibliográfica é o momento inicial de levantamento da literatura sobre o tema.

A análise documental tem como finalidade conhecer o conteúdo dos documentos disponíveis sobre o tema pesquisado. Neste caso, procura-se entender os objetivos, os limites e os desafios enfrentados para a implantação e a execução dos cursos de Licenciatura em Educação do Campo no Estado do Amapá. De acordo com Cellard (2008, p. 295), "o documento escrito constitui uma fonte extremamente preciosa para todo pesquisador nas ciências sociais. [...] muito frequentemente, ele permanece como o único testemunho de atividades particulares ocorridas num passado recente".

Com base nisso, foi realizada a análise das diretrizes de criação do Procampo: Diretrizes Curriculares Nacionais para Formação de Professores da Educação Básica, em nível superior, curso de licenciatura (Parecer CNE/CP no. 9/2001); Diretrizes Operacionais para a Educação Básica nas Escolas do Campo (Resolução no. 1, de 3 de abril de 2002); Licenciatura Plena em Educação do Campo (Minuta original do MEC/Secad); Edital no 2, de 23 de abril de 2008 que fez a chamada pública às universidade para a seleção de projetos para os cursos de formação de professores em Licenciatura em Educação do Campo.

Além das diretrizes nacionais foi realizada a análise do Memorial e do Projeto Pedagógico do curso de Licenciatura Plena em Educação do Campo - área de concentração Física e Biologia, implantado nos Municípios de Laranjal do Jarí e Mazagão, ambos conveniados com o Procampo e sob a coordenação da UNIFAP, a fim de perceber a materialização dos cursos na formação dos profissionais das escolas do campo do Estado do Amapá.

\section{RESULTADOS E DISCUSSÕES}

Os resultados da pesquisa baseiam-se na análise dos documentos e diretrizes de implantação dos cursos no Estado do Amapá. 
Os dados foram obtidos, secundariamente, do memorial do PROCAMPO/UNIFAP.

Conforme consta no referido memorial, as primeiras turmas do curso de Licenciatura em Educação do Campo implantadas nos municípios de Laranjal do Jarí e Mazagão, respectivamente, atenderam 60 acadêmicos, docentes de escolas do campo oriundos dos Estados do Amapá e do Pará, uma vez que o Amapá é responsável pela educação nas aldeias indígenas localizadas no Parque do Tumucumaque/PA (UNIFAP, 2010, p. 16).

A UNIFAP é a instituição responsável por todo o processo de seleção e formação dos educadores e nesse percurso formou 53 professores no campus de Laranjal do Jarí, sendo que 7 evadiram, totalizando $88 \%$ de conclusão e em torno de $12 \%$ de evasão. Na turma do Mazagão formaram-se 40 profissionais no ano de 2015.

A análise socioeconômica feita pela coordenação do Procampo no Estado do Amapá revela que o campo amapaense é um território muito heterogêneo, formado por assentamentos, áreas quilombolas, indígenas, pelas populações tradicionais, pelos ribeirinhos, agricultores, mas apresenta sérias dificuldades na oferta de educação para os sujeitos.

O levantamento sobre o perfil dos acadêmicos em processo de formação mostra um pouco dessa realidade. Além disso, os dados demonstram que apenas $9 \%$ dos profissionais egressos do Procampo mantêm moradia na comunidade em que exerce a docência (Tabela 1).
Tabela 1 Relação residência/local de trabalho dos egressos do Procampo/UNIFAP.

Table 1 Dwelling relationship/workplace of the alumni of Procampo/UNIFAP.

\begin{tabular}{|l|l|l|}
\hline Reside no campo & Não reside no campo & Não respondeu \\
\hline
\end{tabular} $9 \%$ $89 \%$ $2 \%$

Fonte: Elaborado a partir de gráficos da Coordenação Geral do PROCAMPO. Macapá: UNIFAP, 2010.

Um dos problemas enfrentados pelas escolas do campo no Amapá é a falta de vínculo do professor com a comunidade, pois como demonstrado no quadro acima a maioria não reside no campo, são profissionais que passam apenas os períodos letivos nas comunidades. Um agravante a esse processo é que as escolas são afetadas pela alta rotatividade dos professores, deixando, muitas vezes, os educandos por períodos prolongados sem aula, prejudicando a qualidade do ensino, o que recai sobre a aprendizagem, ocasionando a má qualidade e os baixos níveis de escolarização da população.

Nesse sentido, Ferreira (2006, p. 10) discute que para assumir cargo em regiões longínquas, muitos docentes são obrigados a conviver com inúmeras dificuldades, pois muitas comunidades são:

Isoladas e sem nenhuma infraestrutura para a realização do trabalho ou para a sua própria vida pessoal. $O$ sentimento de isolamento e de vulnerabilidade e sem perspectivas tentavam se remover para escolas com mais condições, de preferência na capital.

Esta afirmação traduz a realidade de muitas escolas do campo no Estado do Amapá, pois há comunidades rurais afastadas dos núcleos urbanos que apresentam dificuldade de acesso, principalmente, pela via terrestre. Entretanto, os professores que 
residem e desempenham suas atividades pedagógicas no campo entendem os desafios a serem enfrentados diariamente, seja por questões relativas à falta de estrutura física ou de permanência dos educando, como fica evidente na fala do egresso:

O professor da escola do campo no Amapá tem que ser um guerreiro, tem que enfrentar as dificuldades que não são poucas, a começar pelos prédios das escolas que são precários, isso quando tem prédios, porque em muitos casos as aulas acontecem na sala da casa de alguém da comunidade que cede para funcionar a escola ou quando tem o prédio da escola do município é precário (Informação verbal, 2015, Mazagão).

Nesse depoimento, as dificuldades para o exercício da prática educativa nas escolas do campo aparecem como expressões do cotidiano dos professores. As narrativas estão entrelaçadas pela vida pessoal, social e profissional.

Diante da perspectiva profissional dos egressos, na Tabela 2 abaixo podem ser observados dados específicos sobre o vínculo empregatício durante o período de formação nos cursos do Procampo.

Tabela 2 Vínculo empregatício dos egressos do Procampo/UNIFAP.

Table 2 Employment Bond of the alumni of Procampo/Unifap

\begin{tabular}{|c|c|c|c|}
\hline $\begin{array}{c}\text { Concursado } \\
\text { Estadual }\end{array}$ & $\begin{array}{c}\text { Concursado } \\
\text { Municipal }\end{array}$ & $\begin{array}{c}\text { Contrato } \\
\text { Administrativo }\end{array}$ & Outros \\
\hline $23 \%$ & $47 \%$ & $14 \%$ & $16 \%$ \\
\hline
\end{tabular}

Fonte: Elaborado a partir de gráficos da Coordenação Geral do PROCAMPO. Macapá: UNIFAP, jul. 2010

Nas informações da tabela acima percebe-se que $70 \%$ dos egressos do Procampo é composta de funcionários efetivos da rede pública de ensino na esfera estadual e municipal. Apenas uma pequena parcela é temporária. Acredita-se que o vínculo efetivo é fundamental para diminuir a rotatividade ou a falta de professores nas escolas do campo, uma vez que há perspectiva de permanência desses profissionais atendendo as comunidades rurais. Entretanto, necessita-se de uma política pública de valorização dos docentes como uma das medidas que podem contribuir para a melhoria da qualidade do ensino.

As classes multisseriadas são uma realidade nas escolas do campo no Estado do Amapá. Elas reúnem duas ou mais séries/anos do ensino fundamental. As escolas multisséries dos municípios amapaenses são instituições que apresentam uma vasta diversidade e pluralidade econômica, cultural, ambiental e social que demandam políticas públicas especificas para responder às necessidades da comunidade (Tabela 3 ).

Tabela 3 Exercício da docência em classe multissérie entre os egressos do Procampo/UNIFAP.

Table 3 Exercise of teaching in multigrade class among alumni of Procampo/UNIFAP.

\begin{tabular}{|c|c|}
\hline Docente de classe multisseriada & $\begin{array}{c}\text { Docente de classe não } \\
\text { multisseriada }\end{array}$ \\
\hline $86 \%$ & $14 \%$ \\
\hline
\end{tabular}

Fonte: Elaborado a partir de gráficos da Coordenação Geral do PROCAMPO. Macapá: UNIFAP, jul. 2010

Conforme Azevedo (2010, p. 93), "essas escolas são compreendidas pelo envolvimento com a realidade camponesa - plural e heterogênea - e que evoca saberes próprios, realidades distintas e específicas". As classes multisseriadas representam uma problemática para a organização de uma proposta curricular, porém em muitos lugares do País elas são a única alternativa de acesso à escolarização para os sujeitos do campo.

A capacidade de potencializar condições de acesso às escolas, espaços físicos ade- 
quados e materiais didático-pedagógicos favorece o exercício da cidadania para professores e alunos, tornando a Educação do Campo um elemento preponderante para o desenvolvimento humano e socioeconômico das comunidades rurais do Estado do Amapá.

Concernente às questões pedagógicas, um egresso do Procampo diz que:

Ser um educador do campo no estado do Amapá é uma coisa mirabolante, porque todos os livros e materiais didáticos que vêm para a escola, não são voltados para o nosso meio. O professor que se prontifica a fazer educação do campo aqui tem um trabalho muito maior do que outro profissional que não trabalha no campo, porque ele tem que buscar muita coisa para adaptar para a realidade do aluno, muita coisa mesmo (Informação Verbal, 2015, Mazagão).

Em um contexto marcado pela baixa escolaridade dos sujeitos, o uso de material didático inadequado pelos alunos do campo implica no reconhecimento de que ainda há muito a avançar nesse contexto. Como se pode analisar na declaração do egresso do Procampo, além da dificuldade de acesso e das más condições materiais das escolas do campo, está a inadequação dos livros e materiais didáticos que não são condizentes com a realidade dos educandos, reafirmando um ensino descontextualizado, em que há apenas uma transposição do currículo urbano para o campo. Esse cenário narrado pelo entrevistado é discutido por Reis e Castro (2011, p. 114) que dizem "se buscarmos levantar ao longo da história da educação brasileira, iremos facilmente identificar o descaso com que sempre foi tratada e pensada a educação voltada para a população e educadores do campo".

Diante disso, pode-se afirmar que para exercer a docência nas escolas do campo do Estado do Amapá é necessário superar inúmeros desafios como a falta de material didático e de docentes com formação adequada, tendo então os cursos do Procampo como meio fundamental de consciência crítica e coletiva sobre a realidade. O percurso em um processo de formação acadêmica de professores, naturalmente, vai tornando-se um movimento de ação-reflexãoação intenso e complexo, que leva os sujeitos a construírem novas relações sociais e profissionais com a sua comunidade.

Nesse sentido, a importância dos cursos de LEDOC/Procampo é reconhecida devido ao impacto positivo que deve gerar na formação inicial dos professores e para elevar a qualidade do ensino na educação básica, contribuindo para diminuir a exclusão educacional entre a população do campo que apresenta índices elevados de analfabetismo, abandono e evasão escolar devido à falta de escolas e de educadores que se disponham a exercer a docência nas comunidades rurais do Estado do Amapá.

No Gráfico 1, são apresentados os principais problemas enfrentados pelos egressos do Procampo para exercer a docência s nas escolas do campo no Estado do Amapá. 
Gráfico 1 Descrição das dificuldades enfrentadas nas escolas do campo pelos egressos do PROCAMPO/UNIFAP.

Graph 1 Description of the difficulties faced in rural schools by alumni of Procampo/UNIFAP.
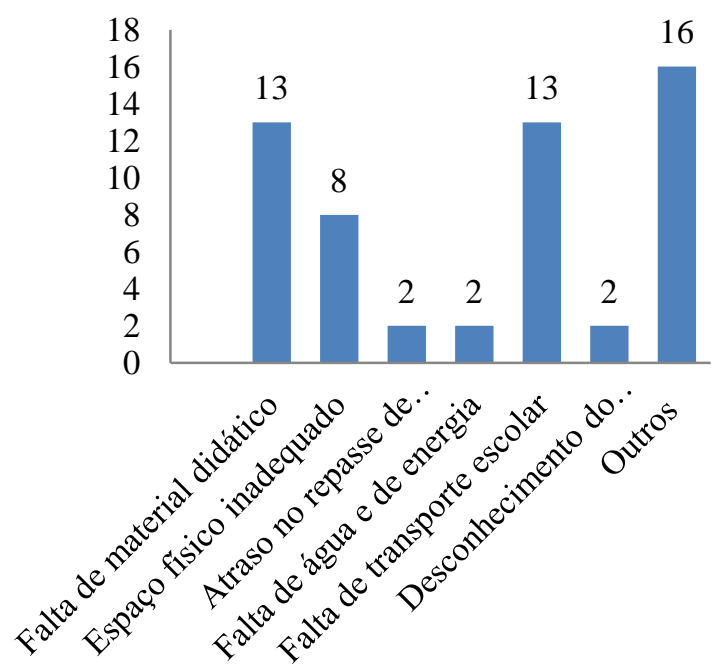

Fonte: Coordenação Geral do PROCAMPO. Macapá: UNIFAP, jul. 2010.

De maneira geral, as questões levantadas sobre as escolas do campo, referem-se a sua precariedade e insuficiência. Diante das informações pontuadas no Gráfico 1, há de se considerar que "[...] a realidade destes sujeitos não costuma ser considerada quando se projeta um desenho de escola" (CALDART, 2007, p. 4) e essas questões transcorrem a história da educação dos povos do campo no sentido de que esta representa apenas um ônus financeiro e a relação custo-benefício é insignificante para o Estado e isto pode ser observado na análise de documentos de períodos anteriores aos anos 1990, período em que as políticas educacionais para o campo eram, praticamente, inexistentes. Corroborando com Arroyo (2007, p. 159), essas políticas vão "adaptando às condições do campo a educação escolar, os currículos e a formação dos profissionais pensados no paradigma urbano".

O aprimoramento do professor é pri- mordial para avançar na qualidade do ensino. Pensar a melhoria da educação do campo é, também, buscar na formação do docente a estratégia para essa mudança, uma vez que "toda formação encerra um projeto de ação e de transformação" (NÓVOA, 1992, p. 31). Nesse sentido, a educação é considerada um elemento importante de transformação social.

Entende-se que os conhecimentos teóricos apresentados na LEDOC/Procampo possibilitaram ao docente "compreender e explicar os processos educativos dos quais participa, como também para contribuir na transformação da realidade educacional no âmbito de seus projetos pessoais e coletivos" (RAMALHO; NUÑEZ; GAUTHIER, 2004, p. 23), tomando suas experiências pedagógicas como ponto de partida.

A promoção da equidade, a garantia de acesso e permanência dos sujeitos do campo em todos os níveis da educação básica e no ensino superior postula a elaboração de políticas públicas adequadas à realidade camponesa. A análise dos documentos e os registros desta pesquisa possibilitaram o entendimento desta formação em Educação do Campo, de um lado, como uma estratégia para a expansão da educação superior e, de outro, como instrumento para qualificar a escola do campo.

\section{CONSIDERAÇÕES}

A partir da década de 1970, o Brasil vem experimentando importantes transformações na estrutura das cidades com a intensificação dos processos de urbanização e industrialização e no campo, principalmente, pela presença do agronegócio e pela demora na execução da Reforma Agrária. No entanto, há um forte movimento de reivindi- 
cações diretamente ligado às lutas das organizações sociais que defendem a garantia de direitos sociais para os trabalhadores que vivem no e do campo.

Com isso, as reivindicações em favor da Educação do Campo ganharam espaço no debate das políticas públicas para a educação. A melhoria dos níveis de aprendizagem exige mudanças na estrutura política, econômica e social, de forma que garantam a democratização do ensino, de forma que os povos do campo tenham a garantia de acesso a todos os níveis da educação.

Diante disso, este texto apresentou reflexões sobre a formação inicial dos profissionais das escolas do campo por meio da Licenciatura em Educação do Campo ofertada pela UNIFAP a partir do financiamento do Procampo, possibilitando compreender os princípios fundamentais da Educação do Campo e o itinerário dessa formação. A carência de docentes qualificados para atender as comunidades rurais do Estado do Amapá constitui-se como um dos pontos nevrálgicos que impedem o avanço na qualidade do ensino. Além disso, as condições de trabalho, de ensino-aprendizagem e a infraestrutura de muitas escolas são precárias e marcadas pela falta de material didático, merenda escolar, transporte, dentre outras.

Diante disso, a LEDOC/Procampo veio suprir a lacuna na formação inicial dos docentes, visando elevar a qualidade do ensino nas escolas do campo no País. O Procampo foi uma política pontual que serviu de base para a implantação dos cursos regulares de Educação do Campo em 42 IES públicas, inclusive na UNIFAP que, desde 2014, passou a ofertar o curso de LEDOC em Ciências Agrárias e Ciências da Natureza no campus do Município de Mazagão.
Os cursos de Educação do Campo trouxeram para dentro das universidades uma nova concepção e racionalidade sobre as licenciaturas, uma vez que, procuram romper com a forma generalista e fragmentada das graduações tradicionais. Com a LEDOC no contexto amapaense, considera-se que os licenciados são capazes de considerar a mobilização social e a ação coletiva dos povos do campo na construção de uma política social emancipadora que os fazem sujeitos históricos comprometidos com o desenvolvimento socioeconômico do campo.

Portanto, a pesquisa de campo nos possibilitou entender que nos cursos do Procampo da UNIFAP todo o processo de formação foi organicamente vivido pelos acadêmicos e professores através de atividades desenvolvidas tanto no âmbito da universidade quanto nas comunidades de origem dos acadêmicos. Nesse processo, os sujeitos do campo têm a oportunidade de compreender a conjuntura histórica das teorias e políticas educacionais e do desenvolvimento rural no contexto amazônico, procurando propor e operar rupturas culturais, sociais, educativas, profissionais em suas convicções e nas concepções que fundamentam sua práxis pedagógica nas escolas do campo.

\section{REFERÊNCIAS}

ARROYO, M. G. Políticas de formação de educadores(as) do campo. Cad. Cedes, Campinas, v. 27, n. 72, p. 157-176, maio/ago. 2007.

AZEVEDO, M. A. de. Avaliação do Programa Escola Ativa Como Política Pública Para Escolas do Campo Com Turmas Multisseriadas: A experiência em Jardim do Seridó/RN (1998-2009). 2010. 215 páginas. (Te- 
se de Doutorado). Universidade Federal do Rio Grande do Norte, Natal, 2010.

BRASIL. Lei 9394 de 20 de dezembro de 1996. Estabelece as Diretrizes e Bases da Educação Nacional. Disponível em: <http:// www.planalto.gov.br>. Acesso em: 20 Jan. 2015.

Lei no 10.172, de 9 de janeiro de 2001. Aprova o Plano Nacional de Educação e dá outras providências. Disponível em: <http://www.mundolegal.com.br/legislação /LEIS/L10172.htm>. Acesso em: 16 jan. de 2015.

Resolução CNE/CEB 1 de 03 de abril de 2002. Institui Diretrizes Operacionais para a Educação Básica das Escolas do Campo. Disponível em: <http://portal.mec. gov.br/cne/arquivos/pdf/rcp01_02.pdf>. Acesso em: 20 de 20 jan. de 2015.

Decreto № 7.352, de 4 de novembro de 2010. Dispõe sobre a Política de Educação do Campo e o Programa Nacional de Educação na Reforma Agrária - PRONERA. Disponível em: <http://www.planalto. gov.br>. Acesso em: 21 de jan. de 2015.

IBGE. Cidades: dados populacionais. 2014. Disponível em: <http://www.ib ge.gov.br/cidadesat/topwindow.htm?1>. Acesso em: 20 de abr. de 2015.

CALDART, R. S. Pedagogia do Movimento Sem Terra. 3. ed. São Paulo: Expressão Popular, 2004.

- Sobre Educação do Campo. In "Campo, Política Pública e Educação". Coleção Por uma Educação do Campo. Brasília: NEAD, 2007.

. Elementos para construção do Projeto Político e Pedagógico da Educação do Campo. In: MOLINA, M. C.; JESUS, S. M. A. de (Orgs.). Contribuições para a construção de um projeto de Educação do Campo. Brasília, 2010.
CELLARD, A. A análise documental. In: POUPART, J. et al. A pesquisa qualitativa: enfoques epistemológicos e metodológicos. Petrópolis, Vozes, 2008.

FERREIRA, M. P. Concurso, ingresso e profissão docente: um estudo de caso dos professores de história (2003-2005). 162 f. Dissertação (Mestrado Educação). PUCSP, Paulo, 2006.

HERKENHOFF, J. B. Constituinte e Educação. In: RAPOSO, G. de R. A educação na Constituição Federal de 1988. Jus Navigandi, Teresina, n. 641, 2005. Disponível em: <http:// jus2.uol.com.br/doutrina/texto.asp?id=657 4>. Acesso em: 03 jul. 2007.

MARTINS, J. S. Reforma Agrária: o impossível diálogo sobre a história possível. In: Tempo Social. Revista de Sociologia da USP. V.11, n.2 (outubro de 1999), editado em fevereiro de 2000. São Paulo: USP, FFLCC. MOLINA, M. C. (org). Educação do Campo e pesquisa II: questões para reflexão. Brasília: MDA/MEC, 2010.

NÓVOA, A. Formação de professores e profissão docente. In: . Os professores e sua formação. Portugal: Publicações Dom Quixote - Instituto de Inovação Educacional e autores, 1992.

OLIVEIRA, M. M. Como fazer pesquisa qualitativa. Petrópolis, Vozes, 2007.

PINHEIRO, O. G. Entrevista: uma prática discursiva In: SPINK,M. J. (org.) Práticas discursivas e produção de sentido no cotidiano: aproximações teóricas e metodológicas. 2. ed. São Paulo: Cortez, 2000, p.183-214. RAMALHO, B. L.; NUÑEZ, I. B.; GAUTHIER, C. Formar o professor, profissionalizar o ensino: perspectivas e desafios. 2 ed. Porto Alegre: Sulinas, 2004.

REIS, J.; L. P.; CASTRO, S. M. V. Panorama da pesquisa em formação de professores: a produção em representações sociais e mé- 
todo (auto) biográfico nos últimos cinco anos. Encontro de pesquisa educacional do Norte e Nordeste. 2011, Manaus. Anais. Manaus: EPENN, 2011.

TAFFAREL, C. Z.; JÚNIOR, S. Políticas Públicas, Educação do Campo e Formação de Professores para as Escolas do Campo. Salvador, EDUFBA, 2011.

UNIFAP. Memorial do Curso de Licenciatura em Educação do Campo. Macapá, 2010. - Projeto Político Pedagógico do

Curso de Licenciatura em Educação do Campo: Docência Multidisciplinar em Física e Biologia. Macapá, 2011.

VENDRAMINI, C. R. Educação e Trabalho: Reflexões em torno dos movimentos sociais do campo. Cadernos do Cedes. Educação do Campo, maio/ago. São Paulo, 2007.

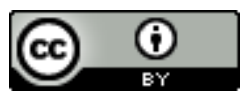

License information: This is an openaccess article distributed under the terms of the Creative Commons Attribution License, which permits unrestricted use, distribution, and reproduction in any medium, provided the original work is properly cited.

Artigo recebido em 10 de outubro de 2015.

Avaliado em 23 de março de 2016.

Aceito em 13 de julho de 2016.

Publicado em 03 de novembro de 2016.

Como citar este artigo (ABNT):

COSTA, Heliadora Georgete Pereira da; LOMBA, Roni Mayer. A expansão da educação superior no Amapá: um estudo sobre o Procampo na UNIFAP. Estação Científica (UNIFAP), Macapá, v. 6, n. 2, p. 91-104, maio/ago. 2016. 